Original Article

\title{
Effect of ankle kinesio taping on vertical jump with run-up and countermovement jump in athletes with ankle functional instability
}

\author{
Yi-Hung Ho, MSc ${ }^{1)}$, Cheng-Feng Lin, PhD ${ }^{2)}$, Chin-Han Chang, $\mathrm{PhD}^{1)}$, Hong-Wen Wu, PhD ${ }^{3 *}$ \\ 1) Department of Biomedical Engineering, National Cheng Kung University, Taiwan \\ 2) Department of Physical Therapy, College of Medicine, National Cheng Kung University, Taiwan \\ 3) Department of Physical Education and Graduate Institute of Physical Education, National Taiwan \\ University of Sport: Taichung 404, Taiwan
}

\begin{abstract}
Purpose] Limited research has been performed in spite of biomechanical evaluation of jump landing with kinesio taping. Therefore, the main objective of this study was to evaluate the effect of kinesio taping applied to athletes. In this study, the authors wished to investigate the effect of kinesio taping during a vertical jump with run-up and countermovement jump on ankle functional instability. [Subjects and Methods] Ten male athletes with ankle functional instability (FI) were recruited in this study from a college volleyball team. Each participant was requested to perform two tasks, the countermovement jump and vertical jump with run-up. Infrared high-speed cameras and force plates were used to assess the effect of ankle taping. [Results] The results showed that the peak ground reaction force in the sagittal plane during a vertical jump with run-up slowed down after kinesio taping and that the peak ankle plantar flexion moment in both types of jump also decreased. [Conclusion] In conclusion, this study proved the effect of kinesio taping on ankle functional instability, which was evaluated by measuring the vertical ground reaction force and peak plantar flexion moment. Its finding may allow us to provide some recommendations for athletes and trainers.

Key words: Kinesio taping, Ankle functional instability
\end{abstract}

(This article was submitted Feb. 13, 2015, and was accepted Mar. 24, 2015)

\section{INTRODUCTION}

Ankle sprain is a common injury for athletes who perform cutting maneuvers, landings, or frequent jumps or make contact with other players ${ }^{1}$. Approximately $40-75 \%$ of individuals develop residual symptoms or chronic ankle dysfunction due to lateral ankle sprain ${ }^{2}$. In addition, functional ankle instability may affect the postural control and whole body balance. Ross et al. quantified the time required for stabilization during single-leg jump landing. They concluded that their functional ankle instability group took significantly longer to stabilize in the sagittal and frontal planes of motion ${ }^{3}$. Based on the findings of the abovementioned studies, individuals with functional ankle instability have a greater risk of injury because of their poor postural control, balance, and proprioception.

Ankle taping has been proved to reduce impact force and to balance the ankle power ${ }^{4)}$. Peak dorsiflexion and average eversion moments were significantly reduced in sidestepping

*Corresponding author. Hong-Wen Wu (E-mail: wuh@ ntupes.edu.tw)

(C2015 The Society of Physical Therapy Science. Published by IPEC Inc. This is an open-access article distributed under the terms of the Creative Commons Attribution Non-Commercial No Derivatives (by-ncnd) License $<$ http://creativecommons.org/licenses/by-nc-nd/3.0/> . tasks after taping ${ }^{5)}$. Proper ankle taping decreases inversion and plantar flexion, which may be related to the most common injury mechanisms ${ }^{6}$. Some scholars also reported that kinesio tape may improve static restraint without altering dynamic postural control or peak motion ${ }^{7)}$. To summarize the above reports, taping and bracing have been widely practiced as both preventative and rehabilitative interventions for ankle sprains by providing mechanical support and enhancing proprioception ${ }^{8)}$.

So far, limited research has been performed in spite of biomechanical evaluation of jump landing with kinesio taping. Further investigation of the effectiveness about kinesio taping is still needed. Therefore, evaluating the effect on athletes during landing is an important issue. The aim of this study was to investigate the effect of the kinesio taping on the ankle functional instability (FI) of athletes during the landing phase in three-dimensional (3D) biomechanics analysis. From the hypothesized biomechanical view, kinesio taping had a positive effect on peak ankle plantar flexion moment and peak vertical ground reaction forces in the FI group.

\section{SUBJECTS AND METHODS}

Ten male athletes with ankle functional instability (FI) were recruited in this study from a college volleyball team. (age, $23 \pm 1.58$ years; height, $172.3 \pm 6.27 \mathrm{~cm}$; weight, $70.2 \pm 9.11 \mathrm{~kg})$. The inclusion criteria of the FI group were 
as follows: (1) no structural instability or other anatomy structure disorder, (2) a feeling of giving way in the ankle joint during exercise or daily activities, and (3) history of ankle sprain, but not in the past six months ${ }^{9}$. Subjects were excluded if painful gait or painful range of motion was observed during the data collection procedure.

Each subject's age, height, weight, and previous injury history were recorded. A physical therapist applied the anterior drawer test and talar tilt test to exclude subjects with ankle mechanical instability.

Each participant was requested to perform two tasks, the countermovement jump and vertical jump with run-up. Each subject rested more than seven days between two conditions (with and without kinesio tape), and performed the countermovement jump and vertical jump with run-up randomly. In the vertical jump with run-up movement, the subjects take a stride with their dominant leg and then jump as high as possible. In the countermovement jump, the subjects start from an upright standing position and then flex the knees and hips to make a preliminary downward movement. The subjects then immediately extend their knees and hips to jump vertically. The subjects were asked to jump as high as possible in both jump movements.

Kinesio tape was applied to each participant's ankle by a professional athletic trainer. The taping methods used included application of tape in the basketweave pattern with application of horseshoe and reinforcing strips ${ }^{10)}$. The tape applied was a 5-cm kinesio tape (Kinesio TEX Products, NKT-050, Japan). The procedure for ankle taping was as follows: the tibialis anterior was taped with elasticity of 60-70\% (Fig. 1a), the Achilles tendon was taped (Fig. 1b), and then the area from the medial malleolus to the lateral malleolus was taped (Fig. 1c). Finally we applied tape with a basketweave pattern, which was followed by application of heel locks with elasticity of 40-50\% (Fig. 1d).

Twenty-one reflective markers were placed on anatomic landmarks of the bilateral lower limbs for each subject. The

a.
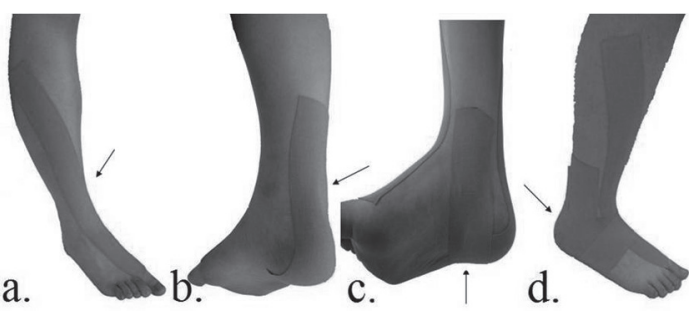

Fig. 1. Kinesio Taping Procedures selected anatomic landmarks were the sacrum, bilateral anterior superior iliac spine, medial and lateral epicondyles of the femur, lateral thigh, lateral shank, calcaneus, medial and lateral malleolus, and base of the second metatarsal bone ${ }^{11)}$. A VICON612 motion analysis system (Oxford Metrics Group, Oxford, UK) with six cameras was used to collect the trajectories of the markers at $250 \mathrm{~Hz}$. Two AMTI force plates (Advanced Mechanical Technology Inc., Watertown, MA, USA) was used to record the ground reaction forces and moments at $1,000 \mathrm{~Hz}$ sampling rates. These two devices were initiated with a trigger, and the synchronization was recorded. The study protocols were approved by the Ethics Committee of National Taiwan College of Physical Education (No. 98002). All participants signed an informed consent form and agreed to participate in the test.

NF1 and NF2 were defined as the first and second peak vertical ground reaction forces normalized by each subject's body weight. $\mathrm{T} 1$ and $\mathrm{T} 2$ were defined as the times to the first and second peak vertical ground reaction forces after landing ${ }^{11)}$.

For smoothing the trajectories of the markers, a generalized cross-validation spline smoothing routine at a cutoff frequency of $6 \mathrm{~Hz}$ was used in this study ${ }^{12)}$. Programs custom made with the MATLAB computer language (The MathWorks, Inc, Natick, MA, USA) were used to calculate the joint moments of the lower limbs using the inverse dynamic method and the parameters of ground reaction forces.

The paired t-test was used to evaluate the effects of ankle taping. The independent $t$ test was used to compare the differences between the countermovement jump and vertical jump with run-up. Ninety-five percent confidence intervals $(95 \% \mathrm{CI})$ were calculated for the difference between groups and conditions. The a priori level of significance was set at 0.05 .

\section{RESULTS}

A statistical significant difference was observed only in the vertical jump with run-up group ( $p=0.02$, Table 1$)$. To further investigate the effect of kinesio taping on the vertical ground reaction force, the first (NF1) and second (NF2) peak vertical ground reaction forces were computed (Table 1 ). We found that the NF2 in the vertical jump with run-up decreased significantly after application of kinesio tape. However, there was no significant difference in NF1 after application of kinesio tape. We then compared the types of jump, and the results showed that larger values were observed for the vertical jump with run-up than the countermovement jump.

Regarding the peak ankle inversion moment, the moment

Table 1. The first (NF1) and second (NF2) peak vertical ground reaction forces normalized by each subject's body weight

\begin{tabular}{lcccc}
\hline \multirow{2}{*}{ Unit $=\mathrm{N} / \mathrm{Kg}$} & \multicolumn{2}{c}{ Countermovement Jump } & \multicolumn{2}{c}{ Vertical jump with run-up } \\
\cline { 2 - 5 } & $\mathrm{NF} 1$ & $\mathrm{NF} 2$ & $\mathrm{NF1}$ & NF2 \\
\hline Non-taped & $1.56 \pm 0.23$ & $4.03 \pm 0.76$ & $1.72 \pm 0.51$ & $5.31 \pm 1.00$ \\
Taped & $1.37 \pm 0.18$ & $3.64 \pm 0.68$ & $1.75 \pm 0.49$ & $4.55 \pm 0.72$ \\
Significance & & & & $\#$ \\
\hline
\end{tabular}

"Significant difference with and without taping $(\mathrm{p}<0.05)$ 
decreased after taping, but no statistical difference was revealed. In addition, there was no significant difference between the two types of jump. Furthermore, a larger plantar flexion moment was measured in the vertical jump with runup than the countermovement jump during landing (Table 2).

The times to the first (T1) and second (T2) peak vertical ground reaction forces after landing are shown in Table 3. No significant difference was observed for the effect of taping on the times to the first (T1) and second (T2) peak vertical ground reaction forces.

\section{DISCUSSION}

A positive effect was observed on the peak vertical ground reaction forces and peak ankle plantar flexion moment in the vertical jump with kinesio taping with run-up. These experimental results provide useful information for attenuating the risk of both jump movements in athletes with ankle functional instability.

Ankle sprains that occur during landing may result from uncertain factors, such as uneven stance and exertion of excessive force. Large ground reaction forces at landing have been reported, and the same results were obtained in this study ${ }^{13)}$.

In the vertical jump with run-up, there was a significant difference in NF2 after taping. It seems that taping has an important effect on the vertical jump with run-up. The findings for the instability group may due to distinct recruitment of muscle fibers of the skeletal muscle during the jump exercise. In the study of Simon et al., it was speculated that an "injured" population with an actual proprioceptive deficit would respond differently ${ }^{14)}$. Ankle functional instability is a proprioceptive deficit. Thus, it is likely more effective for sensory input of the skin to modulate muscle performance. In our study, the knee angle was not controlled in the subject, and this could be a reason why no significant differences occurred during the countermovement jump.

McNitt-Gray reported an NF2 of $4.16 \pm 1.3 \mathrm{~N} / \mathrm{kg}$ (jumping height $0.32 \mathrm{~m})$. The results of the present study were

Table 2. The peak moment of ankle plantar flexion

\begin{tabular}{lccc}
\hline Unit $=\mathrm{Nm} / \mathrm{kg}$ & $\begin{array}{c}\text { Counter- } \\
\text { movement } \\
\text { jump }\end{array}$ & $\begin{array}{c}\text { Vertical jump } \\
\text { with run-up }\end{array}$ & Significance \\
\hline Non-taped & $0.09 \pm 0.04$ & $0.17 \pm 0.06$ & $*$ \\
Taped & $0.06 \pm 0.02$ & $0.12 \pm 0.05$ & \\
Significance & $\#$ & $\#$ & \\
\hline
\end{tabular}

\#Significant difference with and without taping $(\mathrm{p}<0.05)$.

*Significant difference between tasks $(p<0.05)$ in agreement with those of the study of McNitt-Gray ${ }^{13}$. However, Riemann's study revealed that NF1 and NF2 were significantly higher in a non-taped group than a taped group during a jumping motion ${ }^{15}$ ). The difference in NF1 might have been due to the various heights that the subjects jumped. The subjects landed after jumping to a height of $0.59 \mathrm{~m}$ in Riemann's study, while the subjects landed after jumping to a height of only $0.40 \mathrm{~m}$ in this study. A greater jumping height might cause a significant difference in ground reaction. Thus, the difference between the studies may be due to use of different subjects. However, we hypothesize that NF1 and NF2 would decrease after taping.

The ankle plantar flexion moment decreased significantly both in the countermovement jump and vertical jump with run-up after kinesio taping. However, the inversion moment did not decrease when tape was applied. These results were consistent with those of the study of Heit et $\mathrm{al}^{16)}$. They concluded that taping decreased joint position errors in plantar flexion but not inversion. In our results for plantar flexion moment, it appears that application of kinesio tape may restrict the range of motion of the ankle (Table 2). Postural amendment, decreased inflammation and pain, feelings of comfort, and normalization of joint range of motion after application of elastic taping have been pointed out by many scholars ${ }^{9)}$

From a biomechanical perspective, using elastic taping would affect the joint reposition sense and proprioception. Application of kinesio tape may support the muscles and ligaments and reduce sudden force concentration during the landing phase, and it may especially decrease the plantar flexion moment. On the other hand, kinesio taping did not improve the ankle sensory sense in the healthy subjects in the study of Halseth et $\mathrm{al}^{17)}$. The mechanism for instability group whether same for healthy group need to be further discussed.

McNitt-Gray's study reported a mean value of T2 of about $61 \mathrm{~ms}$ for a jump with a height of $0.32 \mathrm{~m}$. In our study, the average jumping height was $0.40 \mathrm{~m}$, and the mean $\mathrm{T} 2$ value was $63.73 \mathrm{~ms}^{13)}$. We believe that these results are very similar.

Nigg mentioned that the duration between muscle contraction for energy absorption and landing was about $50-70 \mathrm{~ms}$. Larger ground reaction forces in this period $(50 \mathrm{~ms})$ would increase the risk of injury ${ }^{18)}$. In our study, the time of the second (T2) peak vertical ground reaction force was often greater than $50 \mathrm{~ms}$, and this may be a reason for recurrence of ankle sprains in countermovement jumping and vertical jumping.

Hubbard et al. concluded that mechanical laxity significantly decreased in ankle instability subjects after tape application ${ }^{19)}$. But in the study of Delahunt et al., the authors

Table 3. The times to the first (T1) and second (T2) peak vertical ground reaction forces after landing

\begin{tabular}{lcccc}
\hline \multirow{2}{*}{ Unit $=\mathrm{ms}$} & \multicolumn{2}{c}{ Countermovement jump } & \multicolumn{2}{c}{ Vertical jump with run-up } \\
\cline { 2 - 5 } & $\mathrm{T} 1$ & $\mathrm{~T} 2$ & $\mathrm{~T} 1$ & $\mathrm{~T} 2$ \\
\hline Non-taped & $11.36 \pm 2.91$ & $62.77 \pm 8.34$ & $10.41 \pm 3.89$ & $53.01 \pm 15.75$ \\
Taped & $13.29 \pm 3.60$ & $66.82 \pm 6.97$ & $10.63 \pm 3.59$ & $53.05 \pm 13.8$ \\
\hline
\end{tabular}


observed no significant change in dynamic postural stability after taping ${ }^{20)}$. In retrospect, there is a clear need for further clinical and science research of taping. The results would help the athletes with ankle functional instability to select appropriate management.

Although we made an effort to investigate the effect of kinesio taping, there are many limitations of this study. Only ten subjects were recruited in this study. This is because very few subjects met the criteria of ankle functional instability. Also, potential subjects were worried about the risk of reinjury and rejected our invitation. Future studies with more subjects are required. The purpose of this study was to understand the impact of ankle taping. We investigated the characteristics of the vertical jump with run-up and countermovement jump in subjects with functional ankle instability. This study proved the beneficial effect of kinesio taping on the ground reaction force in the sagittal plane and peak ankle plantar flexion moment. Fortunately, ankle kinesio taping plays an important role in reducing the moment of the ankle joint. These findings may provide some suggestions for avoiding lateral ankle sprain. In terms of clinical application, kinesio taping may be applied to individuals with ankle instability and may be considered as alternative intervention in the sports rehabilitation field.

\section{REFERENCES}

1) Hosea TM, Carey CC, Harrer MF: The gender issue: epidemiology of ankle injuries in athletes who participate in basketball. Clin Orthop Relat Res, 2000, 372: 45-49. [Medline] [CrossRef]

2) Gerber JP, Williams GN, Scoville CR, et al.: Persistent disability associated with ankle sprains: a prospective examination of an athletic population. Foot Ankle Int, 1998, 19: 653-660. [Medline] [CrossRef]

3) Ross SE, Guskiewicz KM: Examination of static and dynamic postura stability in individuals with functionally stable and unstable ankles. Clin J Sport Med, 2004, 14: 332-338. [Medline] [CrossRef]

4) Semple S, Esterhuysen C, Grace J: The effects of kinesio ankle taping on postural stability in semiprofessional rugby union players. J Phys Ther Sci, 2012, 24: 1239-1242. [CrossRef]
5) Stoffel KK, Nicholls RL, Winata AR, et al.: Effect of ankle taping on knee and ankle joint biomechanics in sporting tasks. Med Sci Sports Exerc, 2010, 42: 2089-2097. [Medline] [CrossRef]

6) Osbahr DC, Drakos MC, O'Loughlin PF, et al.: Syndesmosis and latera ankle sprains in the National Football League. Orthopedics, 2013, 36: e1378-e1384. [Medline] [CrossRef]

7) Akbari A, Sarmadi A, Zafardanesh P: The effect of ankle taping and balance exercises on postural stability indices in healthy women. J Phys Ther Sci, 2014, 26: 763-769. [Medline] [CrossRef]

8) Miller H, Needle AR, Swanik CB, et al.: Role of external prophylactic support in restricting accessory ankle motion after exercise. Foot Ankle Int, 2012, 33: 862-869. [Medline] [CrossRef]

9) Caulfield B, Garrett M: Changes in ground reaction force during jump landing in subjects with functional instability of the ankle joint. Clin Biomech (Bristol, Avon), 2004, 19: 617-621. [Medline] [CrossRef]

10) Kase K, Wallis J: The Latest Kinesio Taping Method. Tokyo: S-journal, 2002

11) Wu HW, Chang YW, Liu CW, et al.: Biomechanical analysis of landing from counter movement jump and vertical jump with run-up in the individuals with functional ankle instability. Int J Sport Exerc Sci, 2010, 2: $43-48$

12) Woltring HJ: A Fortran package for generalized, cross-validatory spline smoothing and differentiation. Adv Eng Software, 1986, 8: 104-113. [CrossRef]

13) McNitt-Gray JL: Original research kinematics and impulse characteristics of drop landings from three heights. J Appl Biomech, 1991, 7: 201-224.

14) Simon J, Garcia W, Docherty CL: The effect of kinesio tape on force sense in people with functional ankle instability. Clin J Sport Med, 2014, 24: 289-294. [Medline] [CrossRef]

15) Riemann BL, Schmitz RJ, Gale M, et al.: Effect of ankle taping and bracing on vertical ground reaction forces during drop landings before and after treadmill jogging. J Orthop Sports Phys Ther, 2002, 32: 628-635. [Medline] [CrossRef]

16) Heit E, Lephart S, Rozzi S: The effect of ankle bracing and taping on joint position sense in the stable ankle. J Sport Rehabil, 1996, 5: 206-213.

17) Halseth $T$, McChesney JW, Debeliso M, et al.: The effects of kinesio ${ }^{\mathrm{TM}}$ taping on proprioception at the ankle. J Sports Sci Med, 2004, 3: 1-7. [Medline]

18) Nigg BM: Biomechanics, load analysis and sports injuries in the lower extremities. Sports Med, 1985, 2: 367-379. [Medline] [CrossRef]

19) Hubbard TJ, Cordova M: Effect of ankle taping on mechanical laxity in chronic ankle instability. Foot Ankle Int, 2010, 31: 499-504. [Medline] [CrossRef]

20) Delahunt E, McGrath A, Doran N, et al.: Effect of taping on actual and perceived dynamic postural stability in persons with chronic ankle instability. Arch Phys Med Rehabil, 2010, 91: 1383-1389. [Medline] [CrossRef] 